\title{
Pharmacokinetics/Pharmacodynamics of Antiviral Agents Used to Treat SARS-CoV-2 and Their Potential Interaction with Drugs and Other Supportive Measures: A Comprehensive Review by the PK/PD of Anti-Infectives Study Group of the European Society of Antimicrobial Agents
}

\author{
Markus Zeitlinger ${ }^{1}\left(\mathbb{D} \cdot\right.$ Birgit C. P. Koch ${ }^{2} \cdot$ Roger Bruggemann $^{3} \cdot$ Pieter De Cock ${ }^{4} \cdot$ Timothy Felton $^{5,6} \cdot$ Maya Hites $^{7}$. \\ Jennifer Le $e^{8}$. Sonia Luque ${ }^{9,10}$. Alasdair P. MacGowan ${ }^{11}$. Deborah J. E. Marriott ${ }^{12,13}$. Anouk E. Muller ${ }^{14}$. \\ Kristina Nadrah ${ }^{15,16}$. David L. Paterson ${ }^{17,18}$. Joseph F. Standing ${ }^{19,20}$. João P. Telles ${ }^{21}$. Michael Wölfl-Duchek ${ }^{22}$. \\ Michael Thy ${ }^{23,24}$. Jason A. Roberts ${ }^{25,26,27,28,29}$ - the PK/PD of Anti-Infectives Study Group (EPASG) of the European \\ Society of Clinical Microbiology, Infectious Diseases (ESCMID)
}

Published online: 28 July 2020

(c) The Author(s) 2020

\begin{abstract}
There is an urgent need to identify optimal antiviral therapies for COVID-19 caused by SARS-CoV-2. We have conducted a rapid and comprehensive review of relevant pharmacological evidence, focusing on (1) the pharmacokinetics (PK) of potential antiviral therapies; (2) coronavirus-specific pharmacodynamics (PD); (3) PK and PD interactions between proposed combination therapies; (4) pharmacology of major supportive therapies; and (5) anticipated drug-drug interactions (DDIs). We found promising in vitro evidence for remdesivir, (hydroxy)chloroquine and favipiravir against SARS-CoV-2; potential clinical benefit in SARS-CoV-2 with remdesivir, the combination of lopinavir/ritonavir (LPV/r) plus ribavirin; and strong evidence for LPV/r plus ribavirin against Middle East Respiratory Syndrome (MERS) for post-exposure prophylaxis in healthcare workers. Despite these emerging data, robust controlled clinical trials assessing patient-centred outcomes remain imperative and clinical data have already reduced expectations with regard to some drugs. Any therapy should be used with caution in the light of potential drug interactions and the uncertainty of optimal doses for treating mild versus serious infections.
\end{abstract}

On behalf of the PK/PD of Anti-Infectives Study Group (EPASG) of the European Society of Clinical Microbiology and Infectious Diseases (ESCMID); all authors are affiliated with this group.

Electronic supplementary material The online version of this article (https://doi.org/10.1007/s40262-020-00924-9) contains supplementary material, which is available to authorized users.

Markus Zeitlinger

markus.zeitlinger@meduniwien.ac.at

Jason A. Roberts

j.roberts2@uq.edu.au

Extended author information available on the last page of the article

\section{Key Points}

The European Society of Clinical Microbiology and Infectious Diseases (ESCMID) PK/PD Study Group has especially convened a group of clinical and PK/ PD experts to provide guidance for all relevant drug therapies for infections caused by the SARS-COV-2 virus. The underlying presents guidance at a high level of detail on the key pharmacokinetic/pharmacodynamic characteristics of drugs at the current most commonly used antiviral regimens, clinically significant drug-drug interactions, and the effect of extracorporeal therapies (e.g. renal replacement therapy, extracorporeal membrane oxygenation) on dosing requirements.

fghcghdff 


\section{Drugs Active Against SARS-CoV-2}

The severe acute respiratory syndrome coronavirus 2 (SARS-CoV-2) was declared a global pandemic on 11 March 2020 and has triggered enormous, unrelenting and everincreasing demands on health systems in countries globally. The number of patients infected with this novel coronavirus escalated dramatically, with the first clinical trial for a vaccine initiated in the US on 16 March 2020. There has been an unprecedented and immediate need to define and optimize treatment for infected patients. However, the evidence for therapies against SARS-CoV-2 is inadequate, leading many medical teams to prescribe drugs based on mechanistic data with limited clinical data supporting their activity. This lack of knowledge is also manifest in highly variable doses or proposed duration of therapy for treatment. It is also noteworthy that many drugs are not uniformly available throughout the world; a therapeutic option for COVID-19 in one country may not be available in another. Inevitably, this heterogeneity of practice and accessibility may lead to patients receiving suboptimal therapy because of a lack of appropriate and readily available data for drugs that are obtainable in a particular country.

Coronaviruses commonly cause infection in non-human animal hosts, and therefore animal models might be informative to investigate drugs that may be applicable for use in humans. Along with preclinical data from animal models, there are emerging reports from in vitro cell culture models that provide information on the mechanism of action and antiviral effects of tested compounds [1]. Application of in silico modeling and simulation techniques can then advance infection model-defined exposure targets to identify doses appropriate for human use. While this process provides highly valuable direction for antiviral therapeutic selection when there is an emergent need for such drugs, these methods are analogous to those applied in the drug development process. The clinical utility of preclinically validated dosing regimens relies heavily on the available pharmacokinetic (PK) data used in the simulation process for the particular drug. That is, PK data obtained from healthy volunteers rather than the population of interest (i.e. severely ill patients with acute respiratory distress syndrome [ARDS]) may not be applicable due to differences in bioavailability for orally or subcutaneously administered drugs, and alterations in the drug's volume of distribution (Vd) and clearance (CL) that may result in sub- or supratherapeutic exposure; therefore careful interpretation for clinical use is essential [2]

Therapeutic agents available for COVID-19 can introduce other treatment challenges, particularly drug interactions. Various compounds that have been proposed for the treatment of SARS-CoV-2 are affected by the cytochrome P450 (CYP)-metabolizing system as either substrates, enzyme inhibitors or enzyme inducers, and consideration of these interactions on dosing requirements of concomitant SARS-CoV-2 or other supportive drug therapies is essential. For instance, lopinavir/ritonavir (LPV/r) combination has strong inhibitory effects on CYP3A4 and CYP2D6, which also metabolize hydroxychloroquine (another probable agent active against SARS-CoV-2), which may result in an increase in potential toxic effects such as Torsades de pointes [3].

With the significant uncertainty regarding the choice and dose of drug therapy for patients with active COVID19 disease, there is a clear need for a review of potential treatments and interpretation of dosing considerations to optimize treatment based on current evidence. The aim of this narrative review is to summarize available literature to guide treatment choices in clinical trials, and to inform local and national policymakers to enable clinicians to optimize the treatment regimens for patients outside trials with SARSCoV-2 infection.

\section{Search Methodology}

Literature regarding the treatment of SARS-CoV-2 is highly dynamic and evolving. Many results have not yet been published in their final form. In order to allow for a fast evaluation of the most relevant treatment practices at hospitals worldwide, the PK/PD of Anti-Infective Study Group (EPASG) of the European Society of Clinical Microbiology and Infectious Diseases (ESCMID) established rapid communication by social media channels. In addition, the World Health Organization website was evaluated for reports pertinent to our review, including preprints [4]

Once the drugs of interest were identified (Table 1) their $\mathrm{PK} /$ pharmacodynamic (PK/PD) characteristics were summarized (Table 2). Subsequently, we searched databases to identify single and combination therapies being evaluated in clinical trials. Searches of the PubMed and Embase databases (no date limits) were then performed using the search strategy '(drug name) AND (coronavirus)' to identify clinical trials, retrospective clinical studies, and animal or in vitro studies on the drug therapies (Table 3 ). In addition, information on drug-drug interactions (DDIs) was extracted [5]. Teams of at least three authors extracted and agreed upon data presented in each table. We deliberately excluded analysis of combinations with remdesivir since the currently open trials investigate only monotherapy.

Because COVID-19 requires intensive care treatment in up to $10 \%$ of infected patients, electronic supplementary Table 1 presents the most commonly used supportive drugs, while electronic supplementary Table 2 presents the potential interactions of these drugs with antivirals. Unless specifically stated, the Summary of Product characteristics 
(SmPC) or package leaflets of medications have been used as the basis for the assessment of DDIs. These interactions are also constantly updated on online platforms, such as the COVID-19 drug interaction webpage maintained by the University of Liverpool [3]. Extracorporeal support treatments might also be necessary for critically ill patients with COVID-19 and, as such, in Table 4 we describe the influence of extracorporeal support treatments on antiviral PK.

\section{List of experimental antiviral agents explored for treatment of Covid 19}

\subsection{Antiviral Agents for the Treatment of COVID-19}

Table 1 contains general information about the key drugs currently suggested for the treatment of COVID-19. Most agents were originally approved for the treatment of other viral infections. The exception is (hydroxy)chloroquine, an immunomodulatory drug with known antiviral activity that has been used for over 60 years, primarily to treat malaria and, more recently, autoimmune diseases, such as systemic lupus erythematosus and inflammatory arthritis. Some of the agents listed have been studied with related viruses, such as Middle East Respiratory Syndrome (MERS) coronavirus. Most agents discussed in this article purportedly have direct mechanisms of action against SARS-CoV-2. As COVID-19 disease has emerged only recently, drugs currently being used are in various phases of clinical trials and none are approved for use in COVID-19, except for the very recent approval of remdesivir. The dosing regimens are based on current knowledge, derived from other indications, and may change in the future when new data become available. Dosing regimens in children are unavailable for most agents. In general, the heterogeneous total daily doses for drugs against COVID-19 disease are similar to, or greater than, that used for other indications.

\subsection{Pharmacokinetics/Pharmacodynamics (PK/ PD) of Antiviral Agents for the Treatment of COVID-19}

Table 2 summarizes the data on the PK/PD properties of the agents recommended for SARS-CoV-2 and other viruses. The available data are limited and are based primarily on in vitro studies in various cell lines. Drug potency is usually presented as the half maximal effective concentration $\left(\mathrm{EC}_{50}\right)$, which varies between viruses. The $\mathrm{EC}_{50}$ values for other viruses are compared against SARS-CoV-2, with a lower $\mathrm{EC}_{50}$ indicating increased potency. While $\mathrm{EC}_{90}$ is usually preferred as a therapeutic target for antivirals, it can only be inferred from $\mathrm{EC}_{50}$ when the Hill coefficient is 1 (in which case $\mathrm{EC}_{90}$ is ninefold higher than $\mathrm{EC}_{50}$ ). Since the
Hill coefficient is not routinely reported, we used $\mathrm{EC}_{50}$ to compare the relative potencies of the antivirals reviewed.

Data on other coronaviruses have been summarized; however, where data are unavailable for coronaviruses, other pathogens are reported. For chloroquine and PegIFN- $\alpha 2 \beta$, measured intracellular concentrations are correlated with the in vitro $\mathrm{EC}_{50}$ and, as such, serve as the PK/PD index [6, 7]; however, there are no studies comparing various PK/PD indices for these agents.

The $\mathrm{EC}_{50}$ values for remdesivir, chloroquine, and ribavirin against SARS-CoV-2 were compared with those of MERS. For both remdesivir and ribavirin, the $\mathrm{EC}_{50}$ values were higher than for MERS, indicating that a larger dose may be needed to treat COVID-19. The $\mathrm{EC}_{50}$ value of chloroquine was within the same range for SARS-CoV-2 and MERS. In an in vitro study, Yao et al. compared chloroquine with hydroxychloroquine and reported that hydroxychloroquine was more potent than chloroquine [7], although caution interpreting these results is warranted since different $\mathrm{EC}_{50}$ values were reported depending on whether experiments were conducted for 24 or $48 \mathrm{~h}$. Since $\mathrm{EC}_{50}$ is not a time-dependent parameter, this calls into question how reliable the estimate is and how well it may translate to an in vivo target. In addition, this study has recently undergone a critical review by authors from the US FDA [8]. Furthermore, other studies have conversely found chloroquine to be more potent than hydroxychloroquine [9], and emerging data from randomized controlled trials (RCTs) [10] and large observational studies [11] suggest that both chloroquine and hydroxychloroquine result in increased mortality when used in COVID-19. While we include chloroquine and hydroxychloroquine in the summary of evidence, there is great uncertainty as to the clinical role of these drugs in hospitalized COVID-19 patients. Indeed, meanwhile, several negative studies have led to discontinuation of the use of these two drugs in many clinical studies in many countries $[12,13]$, yet other countries still continue to use these widely available drugs due to a lack of alternatives.

Several interferons (IFNs), including IFN- $\alpha$, PegIFN- $\alpha 2 \beta$, IFN- $\alpha 1 \beta$ and IFN- $\beta 1 \beta$, have been examined for the treatment of COVID-19; however, they are administered as adjuvant therapy with other anti-COVID-19 drugs.

The currently available data on drug efficacy and PK/PD targets for COVID-19 are inadequate to support therapeutic drug monitoring; however, some data on plasma concentrations are available in the literature (Table 2). When drug concentrations are available in the literature, it may be prudent to evaluate individual concentrations in patients in which high variability in PK combined with an increased likelihood of DDIs and adverse effects can be expected, i.e. typically critically ill patients.

A shortcoming of the data presented in Table 2 is the fact that the total concentrations of the drug were reported by 


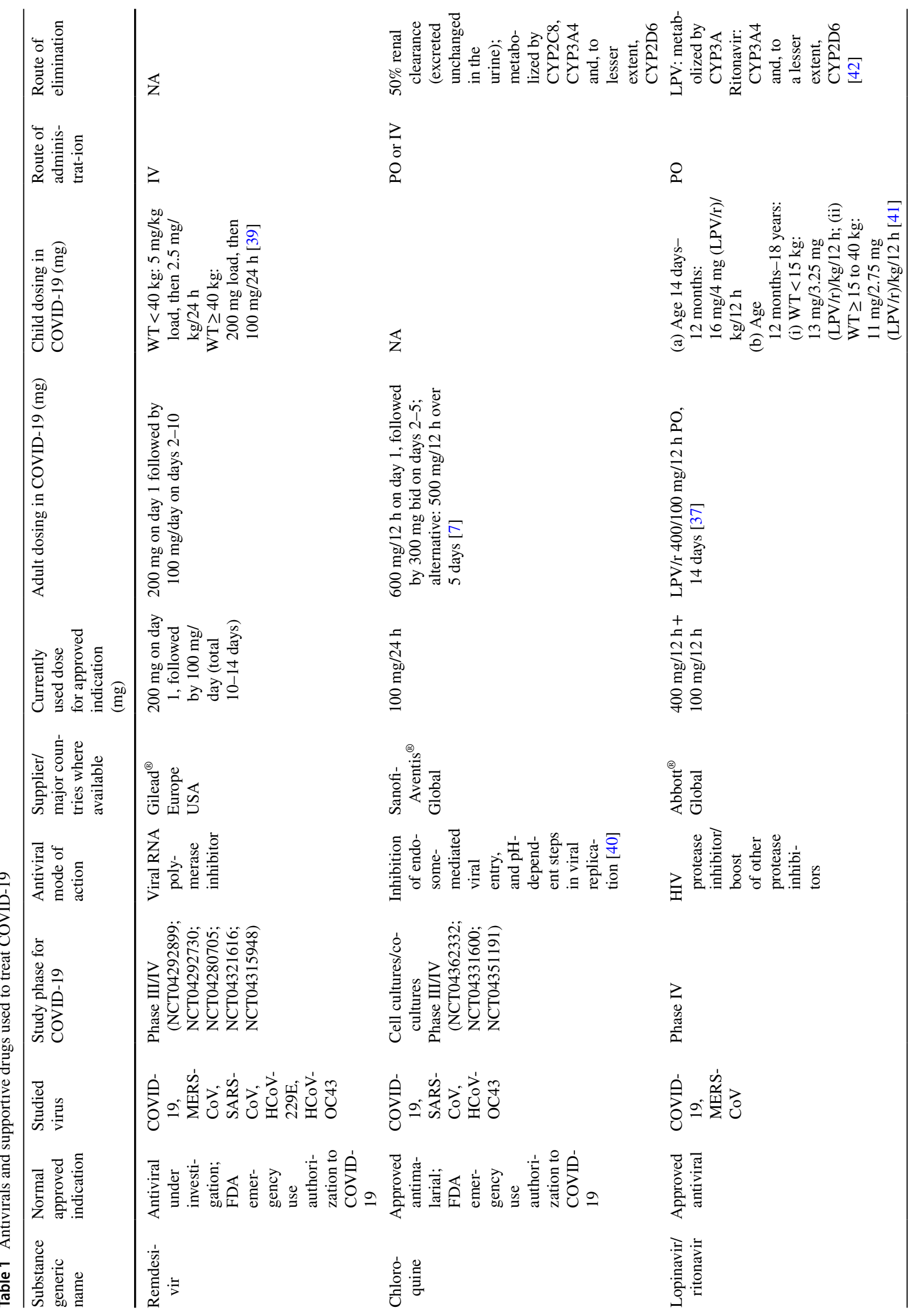




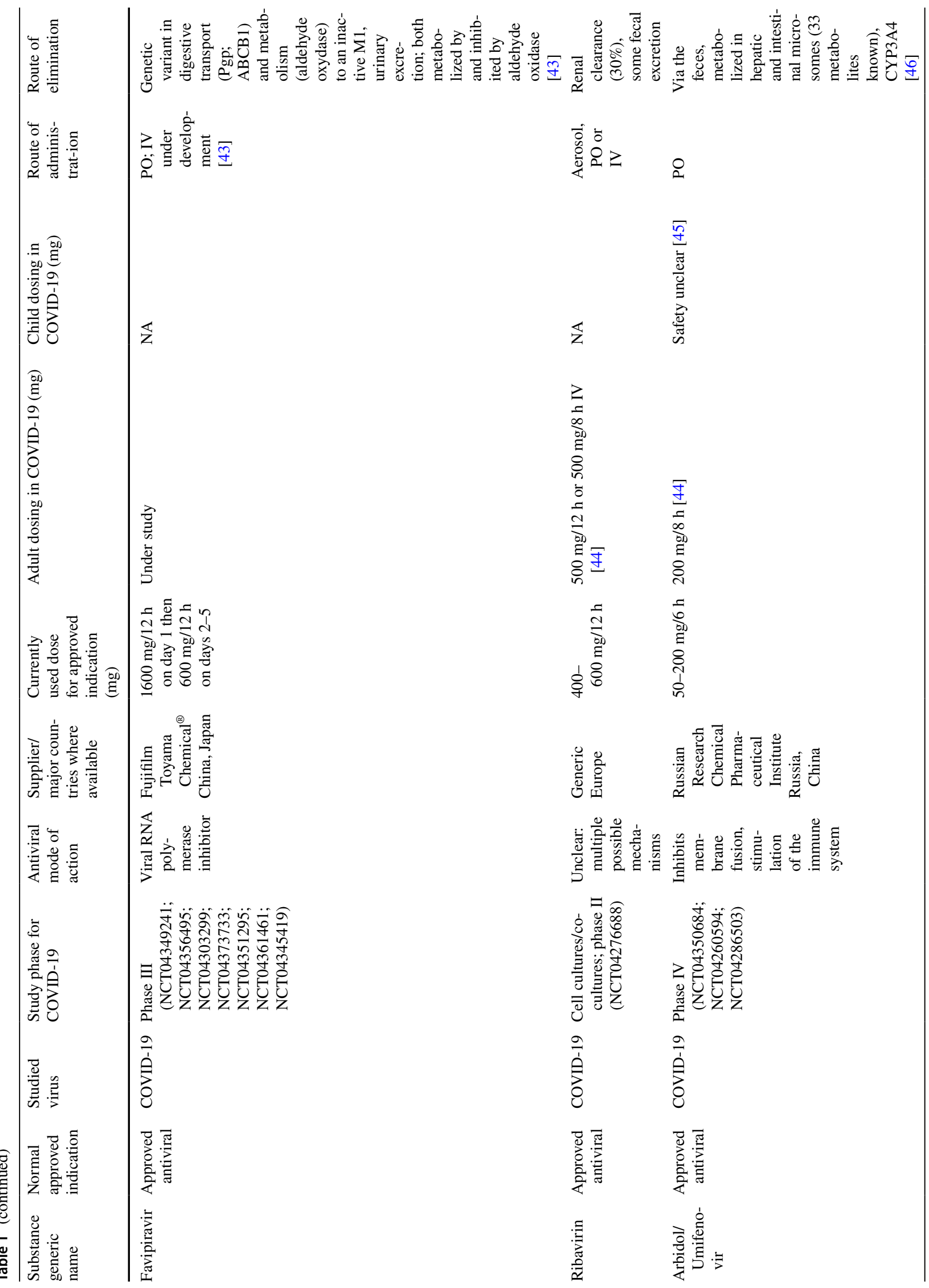




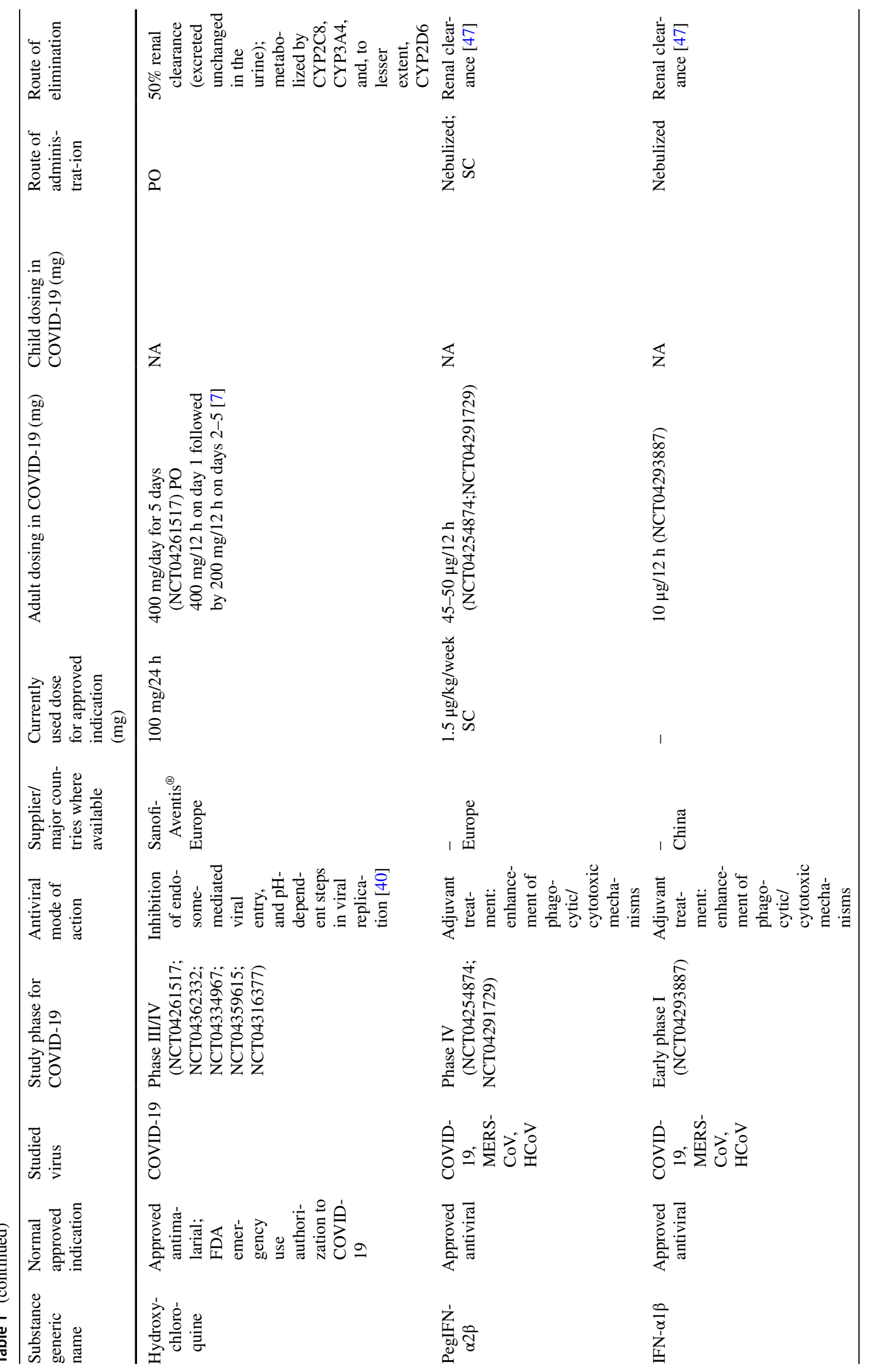




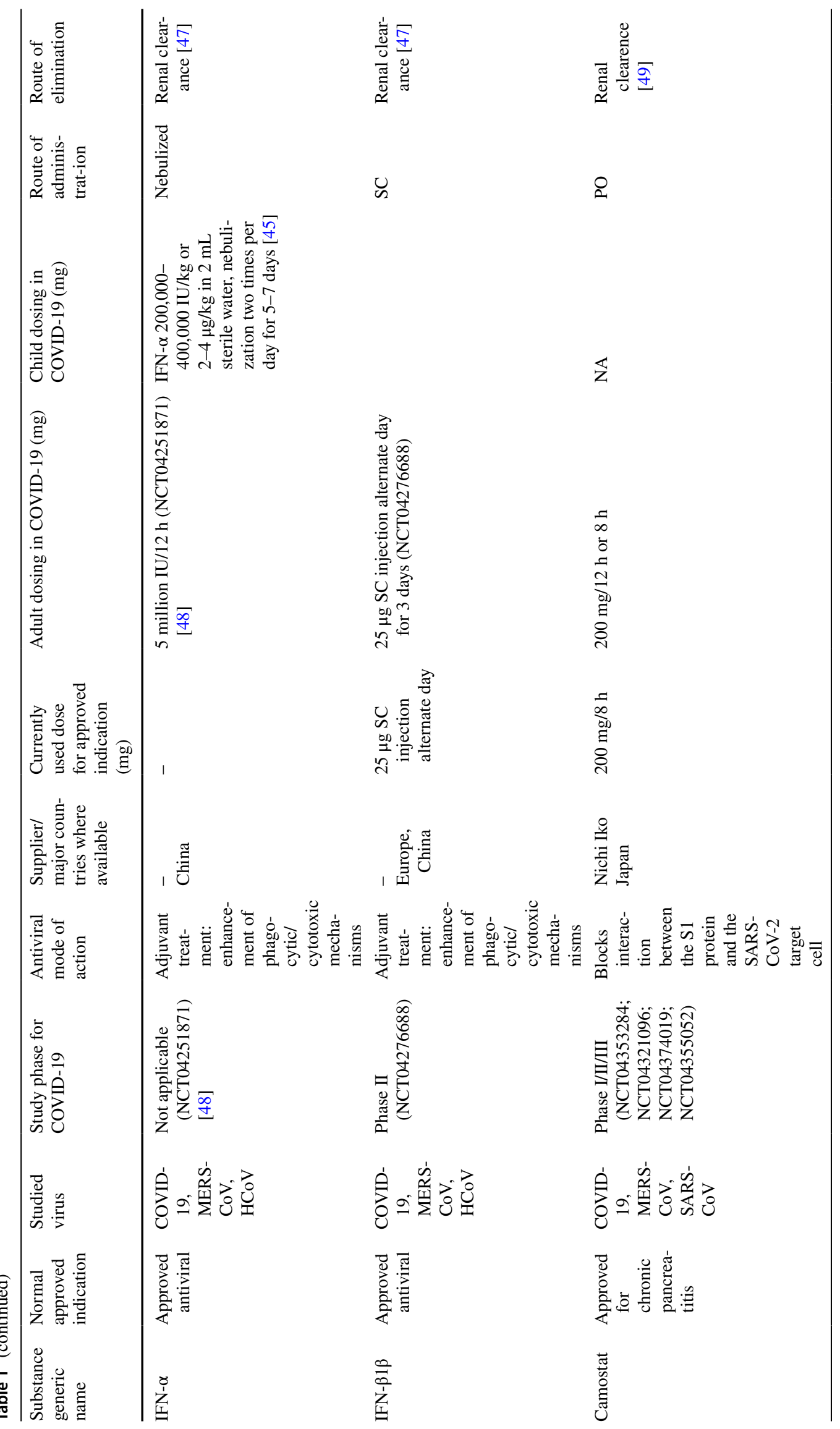




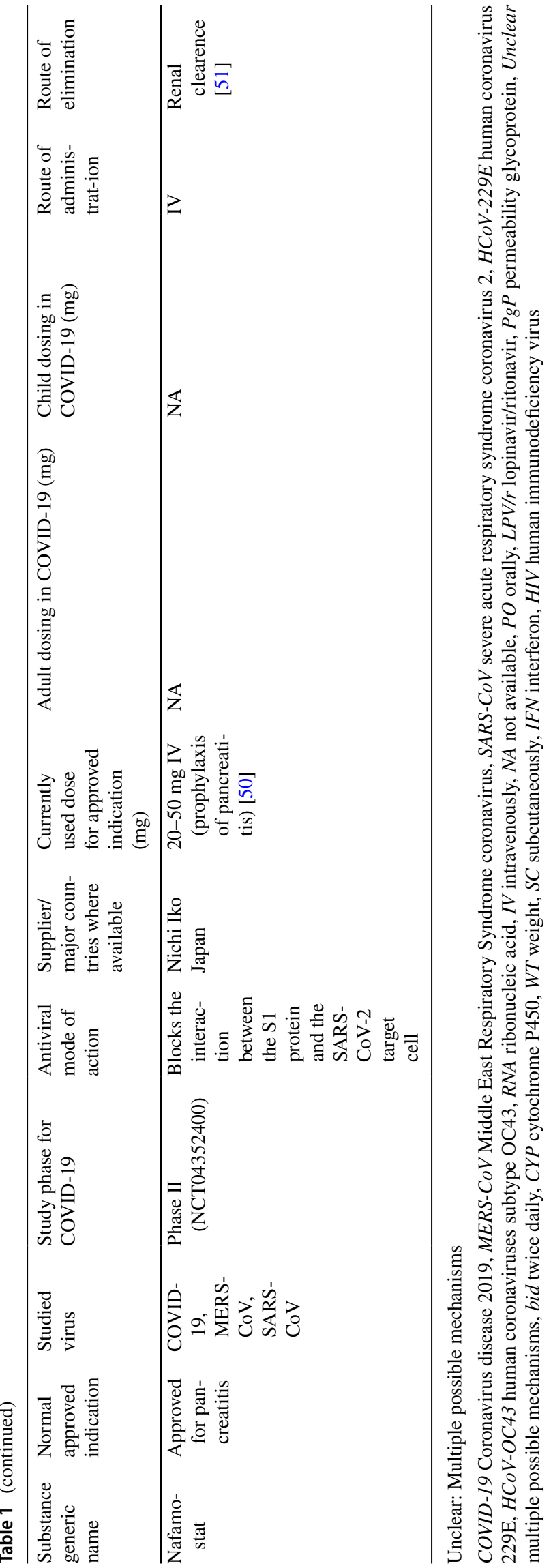

the majority of papers, or information as to whether total or free concentrations were reported is not available at all. This must be taken into account when PK/PD calculations are performed, since, unusually, only the free fraction will be active.

\subsection{Combination SARS-CoV-2 Antiviral Agents and Associated Drug-Drug Interactions}

As there are no approved COVID-19 therapies, combination therapy against SARS-CoV-2 with agents exhibiting different modes of action may have a role in helping to optimize therapy until clinical trial data become available. This combination approach is consistent with the management of many viral, fungal, and bacterial infections where there are suboptimal single-agent treatment options. We aimed to assess the evidence of repurposed antiviral combinations that were not specifically designed to treat SARS-CoV-2.

The strongest RCT evidence exists for remdesivir, which has been shown to reduce the recovery time for moderate-severe COVID-19 in comparison with standard care (11 vs. 15 days [14]; $p<0.001$ ). These data have now led some to declare remdesivir to be the standard of care for COVID-19 disease, even though there was no significant difference in mortality between the remdesivir and standard care groups.

Other, albeit less-compelling, data exist for LPV/r plus ribavirin therapy (retrospective, case-control study) resulting in a reduction in mortality, acute respiratory distress syndrome (ARDS), and viral shedding in the treatment of SARS (Table 3). However, extrapolating these data to SARS-CoV-2 should be undertaken with caution as LPV/r and another HIV protease inhibitor, nelfinavir, exhibit good activity against SARS $[15,16]$ but are less effective against MERS [17]. Another potential combination includes LPV/r, ribavirin and IFN (prospective, non-randomized, comparative controlled study), resulting in shorter duration of viral shedding and hospital stay when compared with LPV/r alone. Randomized trials involving these drugs, based on their promising in vitro activity, will provide important guidance. Of note, we warn against the use of hydroxychloroquine in combination with other drugs that may prolong the QT interval due to potentially life-threatening adverse effects [11]. In a large cohort study, all patients who received hydroxychloroquine for the treatment of pneumonia associated with COVID-19 were at high risk of QTc prolongation, but concurrent treatment with azithromycin was associated with greater changes in QTc [18]. However, since combinations of QTc-prolonging drugs do not necessarily result in additive QTc prolongation, a case-by-case evaluation seems warranted [19]. 


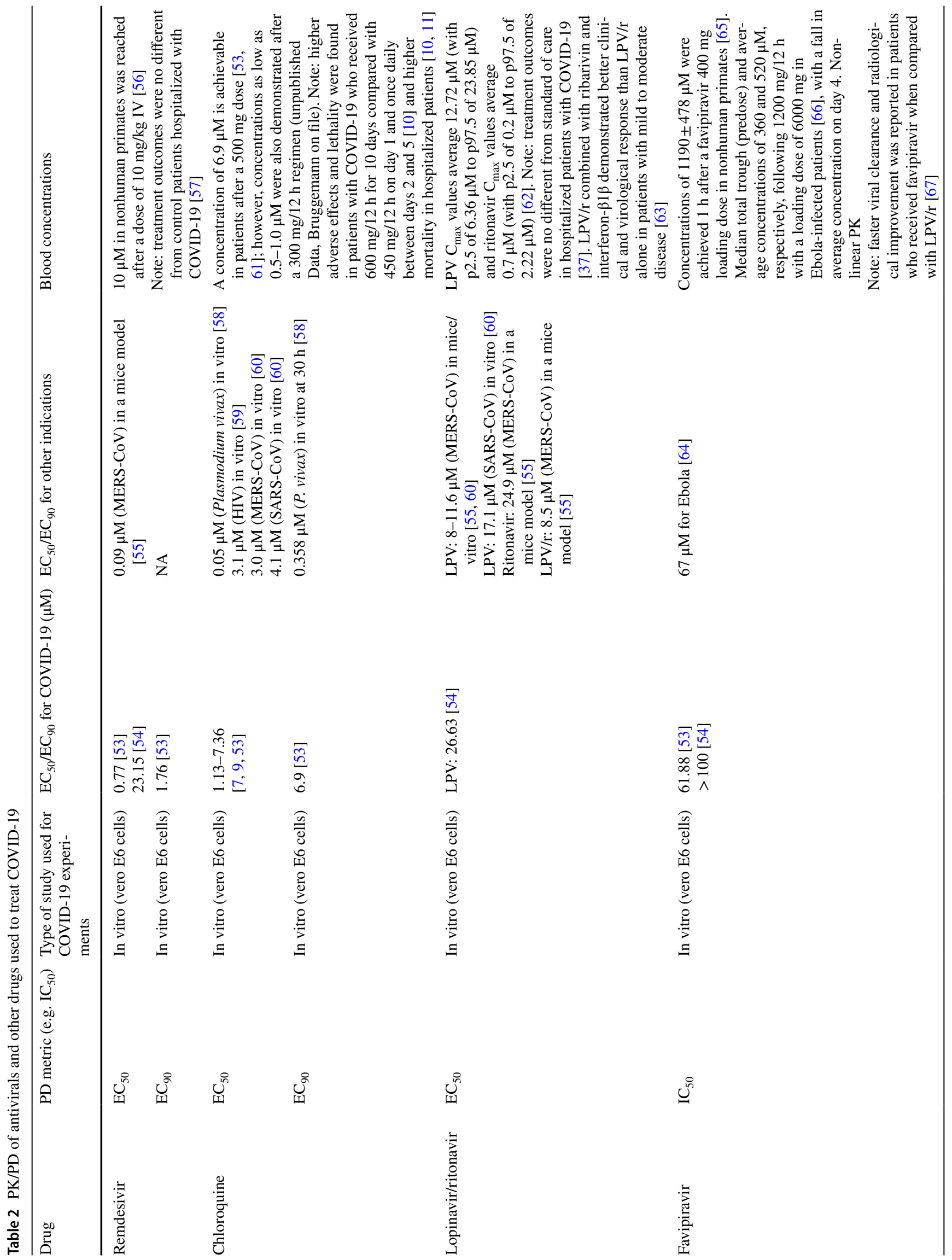




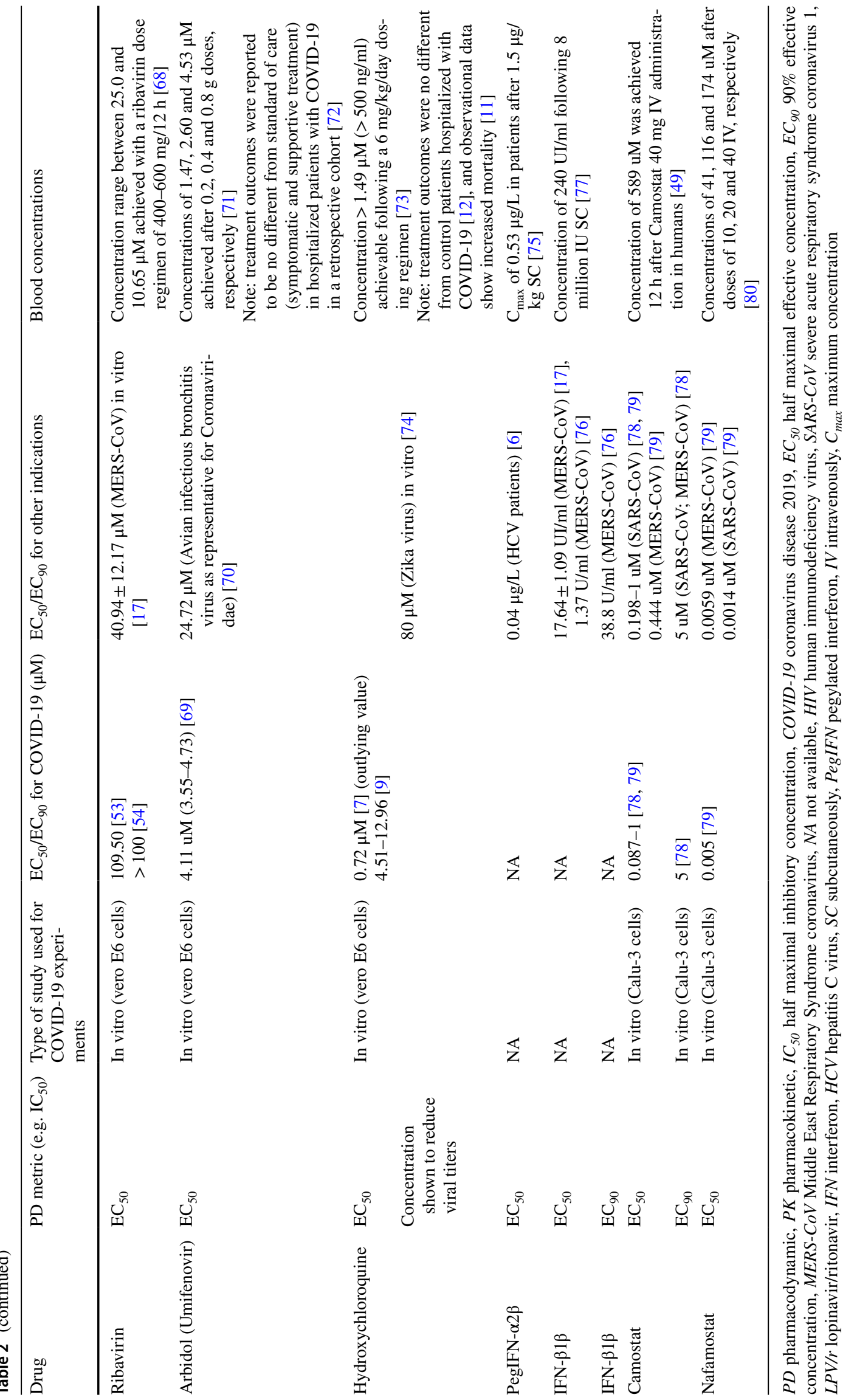




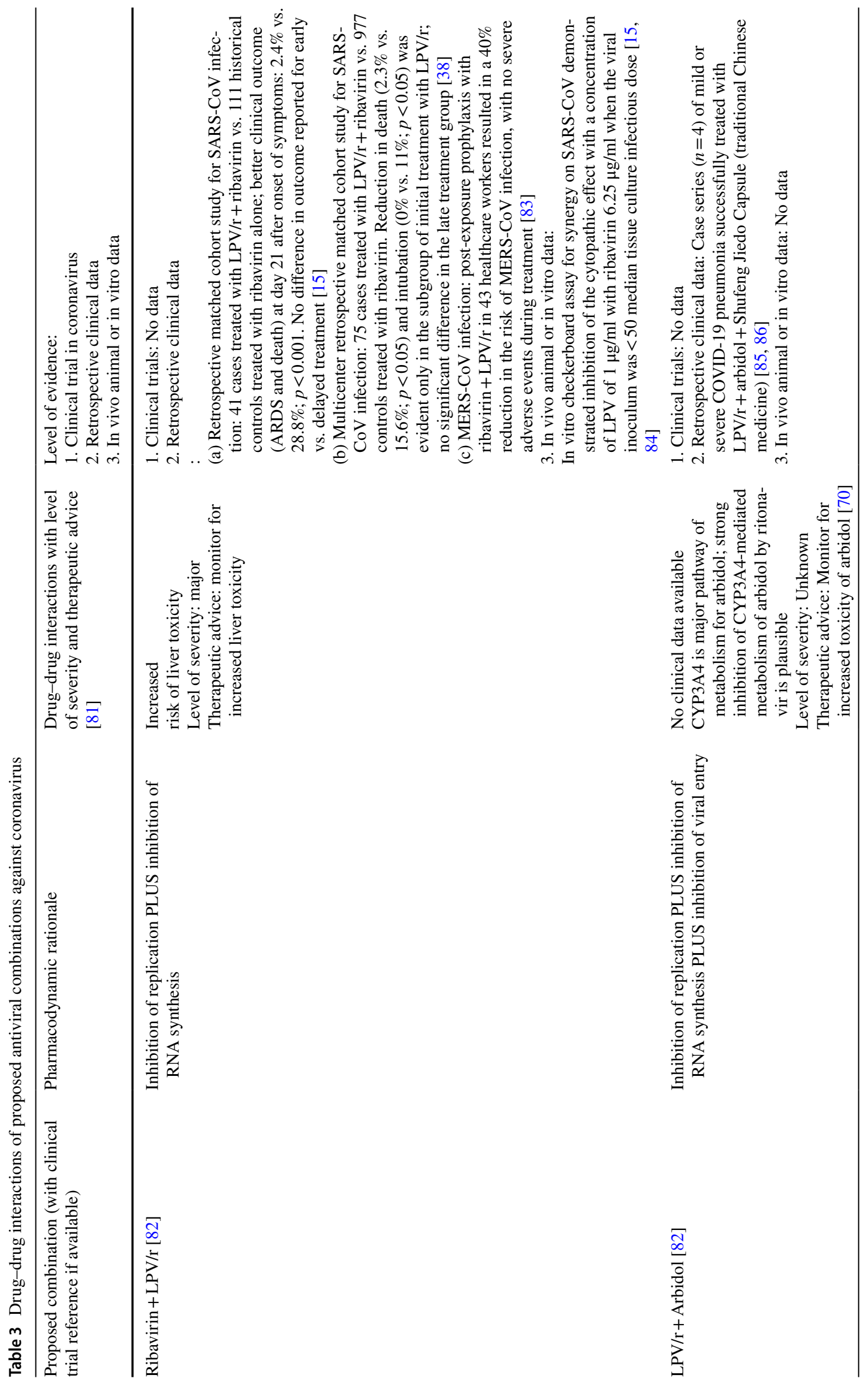




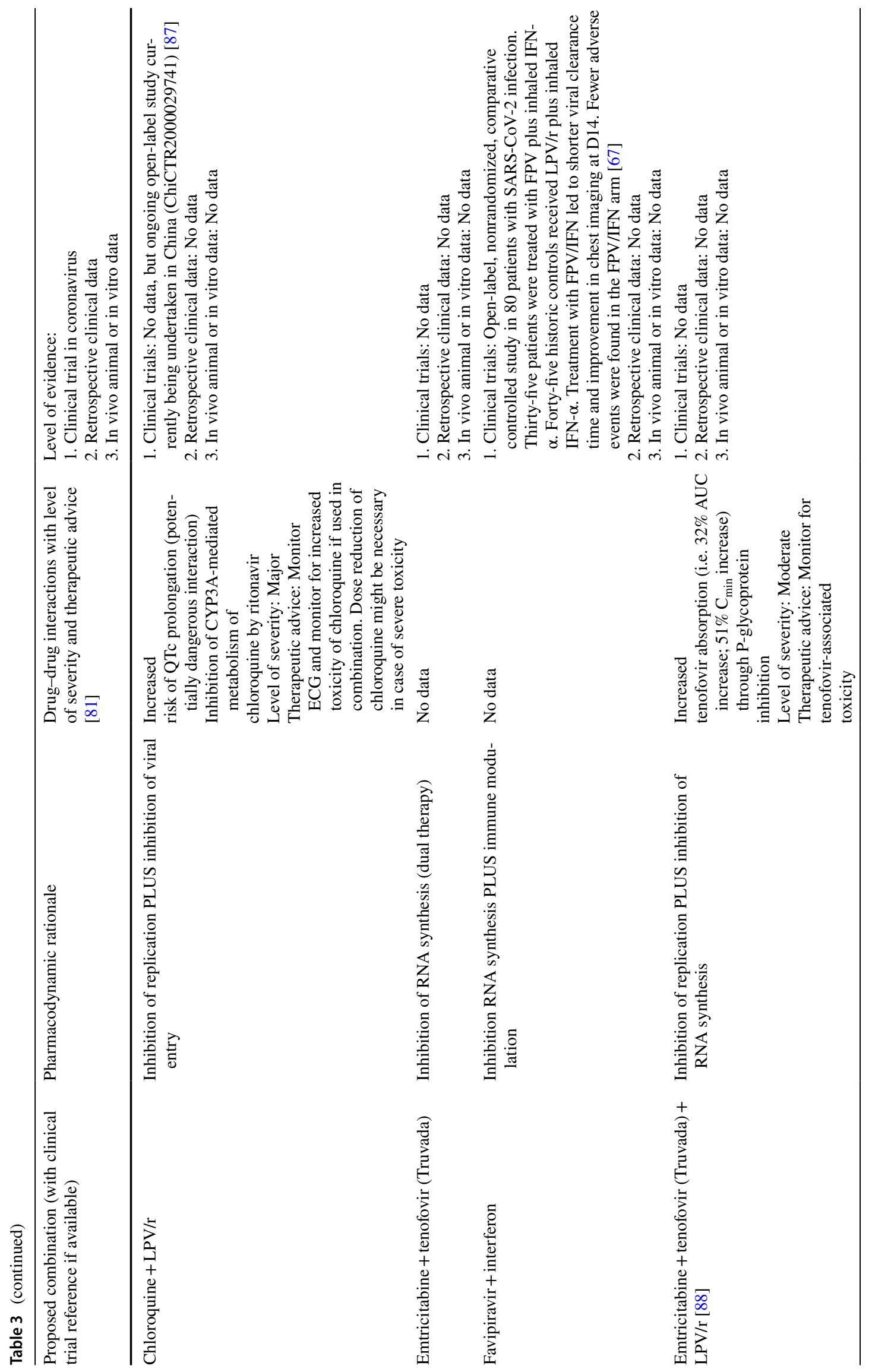




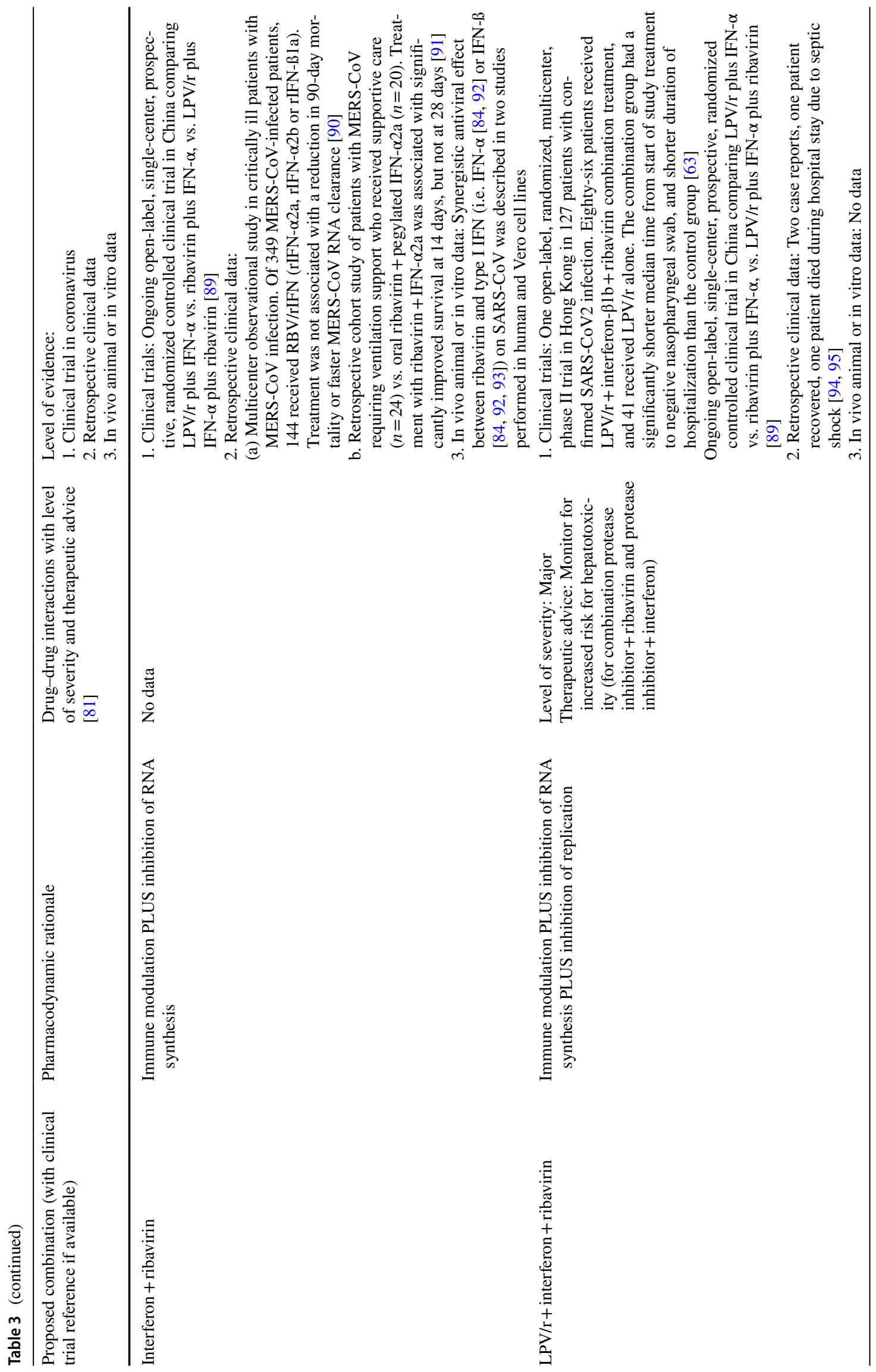




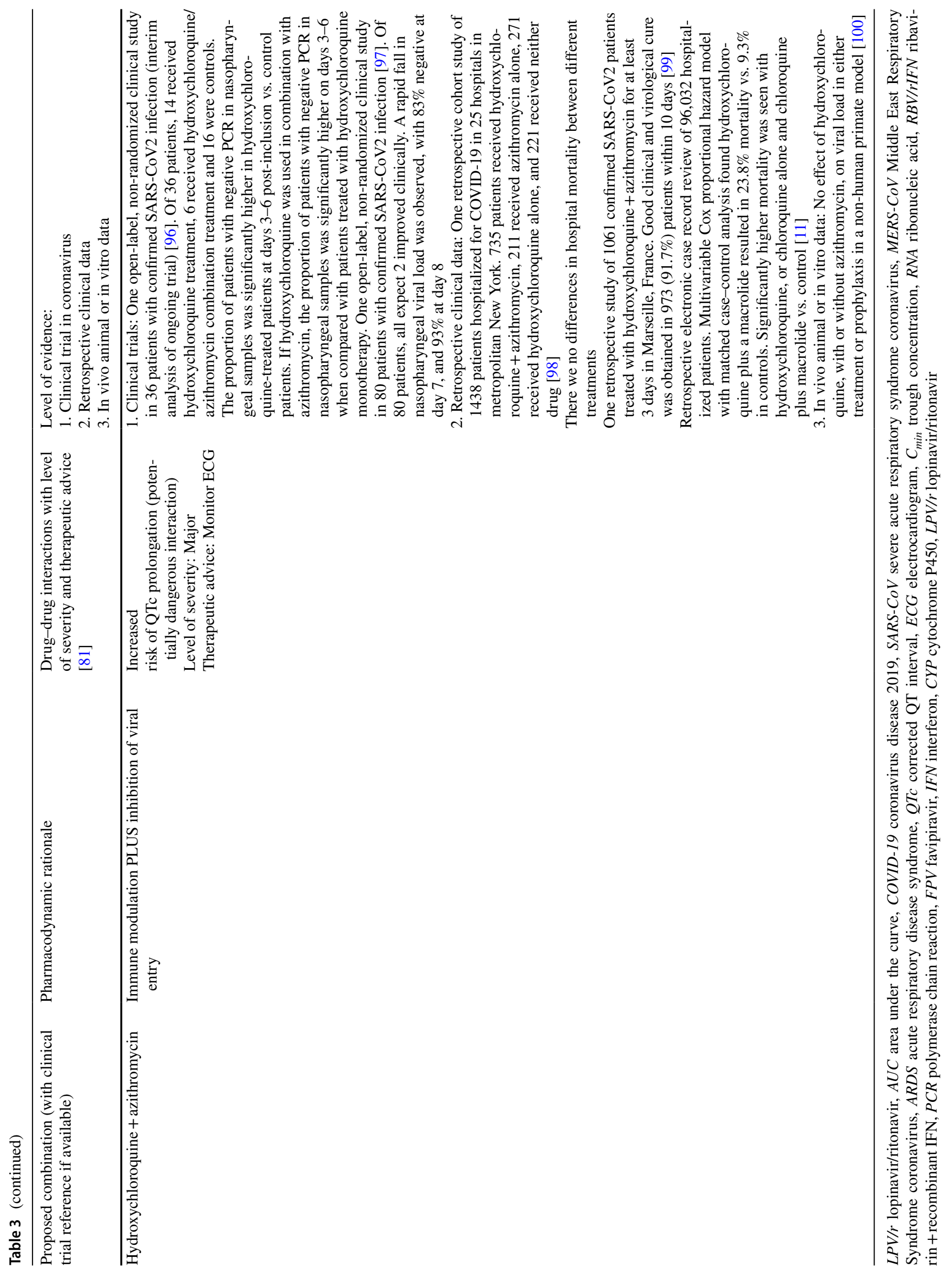




\subsection{Most Commonly Used Supportive Agents (Intensive Care Unit, Pain, Fever, Anticoagulation)}

Supportive care with other pharmacological agents, including antibiotics, sedatives, analgesics, and anticoagulants, need to be considered when treating with antiviral and other repurposed agents, particularly in the critical care setting. Electronic supplementary Table 1 lists the major drugs by class and highlights potential interactions. In particular, caution should be exercised for CYP3A4 DDIs with narrow therapeutic index drugs, such as anticoagulants (warfarin, acenokumarol, dabigatran, rivaroxaban, and apixaban) and immunosuppressant agents in transplant recipients in whom additional monitoring may be required. For patients sedated with midazolam, dose reduction should be considered when patients are treated with CYP3A4 inhibitors, such as LPV/r, as there is a significant risk of oversedation, resulting in unnecessary prolongation of intensive care unit (ICU) stay [20]. There are multiple potential interactions resulting in cardiac complications, including prolonged QT interval with (hydroxy)chloroquine combinations and LPV/r, that necessitate monitoring. As these DDI are substantial, the balance of risk versus benefit should be carefully considered prior to drug administration to prevent significant morbidities.

According to a preliminary report in patients hospitalized with COVID-19, dexamethasone significantly reduced 28-day mortality among those patients receiving invasive mechanical ventilation or oxygen at randomization, but not among patients not receiving respiratory support [21]. If these data hold true, at the moment corticosteroids belong to the most active intervention in patients with severe COVID19 disease. In this aspect, it should also be noted that while dexamethasone is a potent inductor of CYP3A4 induction, this effect seems to be less relevant for the common alternative, betamethasone [22].

\subsection{Interaction Between Antivirals and Supportive Drugs}

The potential interactions for most drugs used to treat COVID-19, and comedications, are provided in detail in electronic supplementary Table 2 . It is emphasized that not all described interactions are necessarily clinically relevant, and the ultimate decision on the need for avoiding a certain combination or dose adjustment must be taken by the treating physician.

DDIs are an important consideration for all therapies used to treat COVID-19. This is especially the case with repurposed antiretroviral drugs and (hydroxy)chloroquine, which have many potential DDIs. Clinicians treating patients infected with SARS-CoV-2 need to carefully consider the potential for DDIs before commencing therapy. Many DDIs may be mitigated by simple measures such as continuous electrocardiogram (ECG) monitoring or by having maximum allowable QT intervals (e.g. $450 \mathrm{~ms}$ ) for the interacting combinations to be used. The ritonavir component of $\mathrm{LPV} / \mathrm{r}$ is deliberately used to inhibit CYP3A4 and thereby increase antiretroviral drug concentrations; however, this leads to a significant potential to increase concentrations of other coadministered therapies that are CYP3A4 substrates. Notably, the interaction between (hydroxy)chloroquine and other agents that may inhibit drug CL can result in cardiac toxicity and patients should be monitored closely. Based on the long half-life of (hydroxy)chloroquine (in the magnitude of several weeks), interactions might persist for several days after treatment has ceased. This may be especially problematic in critically ill patients with pre-existing cardiovascular morbidity, and extreme caution should be observed. The use of triazole antifungals should be avoided or carefully monitored if administered concurrently with LPV/r due to DDIs. Potential DDIs are reported between either LPV/r and important drugs commonly used in the critical care setting, including ketamine, rocuronium, and many of the opioid agents. Utmost care is required when considering the coadministration of these agents with antiretroviral drugs in critically ill patients. The newer investigational antiviral agents, remdesivir and favipiravir, appear to have a lower potential for DDIs; however, the main concern with their use is decreased concentrations if coadministered with enzyme inducers. (Hydroxy)chloroquine may prolong the QT interval, therefore ECG monitoring is required when they are coadministered with other agents known to cause QT interval prolongation. Coadministration of (hydroxy)chloroquine with drugs that are known to prolong the QT interval, such as amiodarone and flecanide, is not recommended. However, clinical experience with these drugs is much less than the repurposed antiretrovirals. A comprehensive and evolving DDI database has been created by the University of Liverpool and this should be consulted for potential DDIs not covered in our review [3].

\subsection{The Effect of Extracorporeal Treatments on the PK of COVID-19 Therapies}

Systemic inflammatory response syndrome (SIRS) may occur with the use of extracorporeal treatments, and may cause alterations in CYP-mediated metabolism. SIRS increases activity of all CYPs, except CYP3A4, which decreases. In children, CYP enzymes are commonly immature in neonates and take time to reach similar activity levels as adults [23]. In this section, as well as in Table 4, we summarize the principles of PK alterations that occur with extracorporeal membrane oxygenation (ECMO) and renal replacement therapy (RRT) to impact drug exposure and thereby dose. Although limited studies have been conducted 
Table 4 Expected PK of the antivirals used to treat COVID-19 with extracorporeal support treatments

\begin{tabular}{|c|c|c|c|c|}
\hline \multirow{2}{*}{ Name of antiviral } & \multicolumn{3}{|c|}{ Effects on pharmacokinetic parameters } & \multirow[t]{2}{*}{ Protein binding $(\%)$} \\
\hline & RRT & ECMO & Extracorporeal systemic inflammatory response ${ }^{a}$ & \\
\hline Remdesivir & NA & NA & NA & NA \\
\hline Chloroquine & - & Likely ${ }^{\mathrm{b}}$ & Alterations in cytochrome metabolism & $40-60[25,31]$ \\
\hline Lopinavir & - & Likely ${ }^{\mathrm{b}}$ & Alterations in cytochrome metabolism & $98-99[101]$ \\
\hline Ritonavir & - & Likely $^{\mathrm{b}}$ & Alterations in cytochrome metabolism & 99 [102] \\
\hline Favipiravir & - & Increases Vd & Alterations in cytochrome metabolism & $54[32]$ \\
\hline Ribavirin & - & Increases Vd & - & $0[26]$ \\
\hline Arbidol (Umifenovir) & - & - & Alterations in cytochrome metabolism & NA \\
\hline Hydroxychloroquine & - & Likelyb & Alterations in cytochrome metabolism & $40-60[25,31]$ \\
\hline PegIFN- $\alpha 2 \beta$ & - & - & - & NA \\
\hline IFN- $\alpha 1 \beta$ & - & - & - & NA \\
\hline IFN- $\alpha$ & - & - & - & NA \\
\hline
\end{tabular}

$R R T$ renal replacement therapies, $E C M O$ extracorporeal membrane oxygenation, $N A$ not available, $V d$ volume of distribution, $I F N$ interferon

${ }^{a}$ For example, systemic inflammatory response syndrome (SIRS) caused by extracorporeal life support system

${ }^{\mathrm{b}}$ Sequestration of drug to the ECMO oxygenator is likely, but is unlikely to affect dosing needs

on COVID-19 therapies, optimized dosing should consider these potential impacts on individual patients.

\subsection{The Impact of Extracorporeal Membrane Oxygenation}

The most common mechanisms by which ECMO is likely to affect the PK of drugs are sequestration by the oxygenator and tubing in the ECMO circuit, leading to reduced circulating drug concentrations [23]. While lipophilic drugs and highly protein-bound drugs are more likely to be sequestered in the circuit, hydrophilic drugs can be significantly affected by hemodilution and changes in albumin concentration, potentially leading to altered protein binding and an increased Vd. Indeed, an increased free fraction means more distribution from the central compartment into the peripheral compartments (i.e. tissues), leading to an increased apparent $\mathrm{Vd}[24]$

\subsection{The Impact of Renal Replacement Therapy}

Sepsis-related acute kidney injury often develops in the context of multiple organ dysfunction syndrome and leads to relevant modifications of several PK parameters. Moreover, high volumes of fluid resuscitation, commonly required in critically ill patients [25], may significantly affect the $\mathrm{Vd}$ of several drugs [26]. When Vd of a drug is typically small since the drug is mostly retained in the intravascular compartment (where protein binding is high), clinically significant removal of small drugs by RRT is unlikely. Where $\mathrm{Vd}$ is $<1.0 \mathrm{~L} / \mathrm{kg}$ and protein binding is not high ( $>80 \%$ ), the commencement of RRT adds further complexities for dosing, with possible extracorporeal CL. Renally excreted drugs are usually affected by RRT to a much greater extent than hepatically excreted drugs [27]. Only the free (i.e. unbound) drug is cleared across the RRT filter. With the exception of a few drugs, the molecular weight (MW) of the most commonly used antimicrobial agents is lower than $1000 \mathrm{Da}$ and plays a key role, especially in diffusive RRT modalities, as the sieving coefficient (SC) of a molecule is inversely proportional to $\mathrm{MW}$. The SC is generally similar for drugs with a MW around 1000-1500 Da in convective modalities. However, in diffusive techniques, the ratio of dialysate to plasma solute concentration (saturation coefficient $[\mathrm{SA}]$ ) is more strictly dependent on MW and tends to decrease progressively as MW increases [28]. Whereas intermittent hemodialysis (IHD) or continuous venovenous hemodialysis (CVVHD) are essentially diffusive techniques, continuous venovenous hemofiltration $(\mathrm{CVVH})$ is a convective technique, and continuous venovenous hemodiafiltration (CVVHDF) is a combination of both. As a general rule, the efficiency of drug removal by the different techniques is expected to be CVVHDF $>$ CVVH $>$ CVVHD/IHD, but this can still vary greatly depending on the physicochemical properties of each drug and the CRRT settings [29]. Dialyzer membrane characteristics (cut-off) may also play a key role.

\subsection{PK Data of Drugs Active Against SARS-CoV-2}

Table 4 extrapolates basic drug physicochemistry and known PK data to predict the likely effects of ECMO on PK. Sparse data on the IHD CL of (hydroxy)chloroquine are available and suggest that the high $\mathrm{Vd}$ of (hydroxy)chloroquine limits significant alteration in drug concentrations [30]. As such, ECMO is predicted to have minimal impact on the drug 
concentrations of (hydroxy)chloroquine, although sequestration onto the oxygenator and circuit tubing cannot be excluded. There is also the hypothesis that (hydroxy)chloroquine rapidly partitions intracellularly, potentially resulting in minor effects overall and in the vascular compartment [25]. The PK of LPV/r in hemodialysis suggests that dosing adjustments are unnecessary in treatment-naive patients, in part due to the high protein binding of these drugs [31]. CVVH has no clinically relevant contribution to total CL of favipiravir [32]. For ribavirin, CL was reduced by $50 \%$ via IHD [33], which is not considered significant enough to justify increasing the dose based on increases in dialysate or RRT filtration flow rate [34]. No significant effect of RRT on IFN concentrations is predicted due to the MW of the IFN compounds which usually exceeds $15 \mathrm{kDa}[35,36]$.

\section{Discussion}

We have provided an in-depth rapid review on the preclinical and clinical antiviral treatment options for SARS-CoV-2. It should be emphasized that although the approach in the current review is pragmatic to allow for real-time assessment of international practice, it cannot guarantee that all experimental combinations have been captured. However, the therapeutic investigations for COVID-19 are highly dynamic and almost daily new treatment options are empirically tested in clinical practice globally. More importantly, the quality of data regarding the safe and effective use of treatment options are generally poor and strong recommendations cannot be provided regarding the superiority of one treatment or combination over another. It is clear with absolute certainty that robust controlled clinical trials are imperative. Such studies must use either clinical endpoints (demonstrating a benefit in how the patient feels, functions, or survives) or improving meaningful biomarker performance such as time of viral shedding. Regarding the study design, randomization, blinding, and an appropriate control (either a comparator that has been proven effective or placebo) are recommended. Meanwhile, all antiviral therapies should be used with caution due to the significant drug interactions, risk for adverse events, and the need to evaluate optimal doses for treating mild versus serious infections.

All drugs presented in Table 1 should be seen as possible treatment options for patients with, or very likely to develop, a critical COVID-19 disease despite no strong recommendations being available. We found that PK/PD indices indicate that many of the currently used treatment regimens fail to achieve sufficient concentrations when $\mathrm{EC}_{50}$ values are compared with plasma PK, which might partially explain limited clinical success of these combinations. Before investigation of any new combination empirically, PK/PD models with Monte Carlo simulations should be used to predict success and, wherever possible, integrate an adaptive design to also account for tolerability. Failure to develop these models might lead to suboptimal drug exposure in patients, resulting in erroneous omission of therapeutic options before exploring their full potential.

Relevant DDIs exist both between combinations of antivirals and between antivirals and supportive therapies. Since many of the combinations have not been widely used in the ICU, healthcare providers should be alerted to closely monitor for DDIs. With the omnipresent work overload related to the COVID-19 crisis within hospitals and ICUs, applications (apps) or programs should be developed to support real-time clinical decisions and dose adaption.

A recent study of LPV/r showed no effect against SARSCoV-2 [37] but this conclusion should be interpreted with caution. Only 199 patients were randomized and the nonsignificant trend showed a 5.8\% decrease in mortality with $\mathrm{LPV} / \mathrm{r}$ versus no treatment. If this is the true effect size, a larger sample size is required. Furthermore, the high overall mortality reported in this study suggests that these patients had severe disease, and the late initiation of therapy (i.e. within 12 days after the onset of symptoms) may have affected the results. As such, the clinical benefit of early initiation of LPV/r monotherapy should be further investigated. The clinical trials of SARS or MERS evaluated LPV/r in combination with ribavirin, rather than as monotherapy. Lopinavir and ribavirin have been found to be synergistic in vitro against SARS [15], and, more importantly, the combination of LPV/r and ribavirin reduced mortality and viral shedding when compared with historical controls [15]. Another study in SARS reported that early initiation of combination therapy consisting of LPV/r plus ribavirin, compared with historical controls treated with ribavirin alone, significantly reduced mortality and the need for ventilation; notably, there was no effect with delayed or late therapy [38]. Extrapolating these data to SARS-CoV-2 should be taken with caution since LPV and the protease inhibitor nelfinavir appears to exhibit good activity against SARS [16] but is less effective against MERS [17]. Nonetheless, LPV/r, ribavirin and IFN combinations should be investigated for in vitro synergy against SARS-CoV-2, and considered for clinical evaluation if the results are promising. One open-label RCT comparing LPV/r plus inhaled IFN- $\beta$ plus ribavirin against $\mathrm{LPV} / \mathrm{r}$ in SARS-CoV-2-positive patients reported a significantly shorter time from start of treatment to negative nasopharyngeal swab, and shorter duration of hospitalization, when compared with the control group. Of note, we advise against the use of combinations of hydroxychloroquine with azithromycin due to emerging safety issues with this drug combination, in particular increased risk for QTc prolongation [18].

In summary, there are promising therapeutic options for COVID-19 in the absence of a vaccine at present. The 
encouraging RCT results for remdesivir provide some direction for the treatment of COVID-19 patients and has led to positive evaluation of the drug for severe forms of COVID19 by the European Medicines Agency and the FDA. Further to this, it is highly likely that one or more other agents mentioned in this review, or, more plausibly, a combination, may emerge as a prophylactic or early treatment option with the potential to decrease viral shedding and transmission and/ or reduce disease progression to the requirement of ventilatory support.

From a PK/PD perspective, the development should not only focus on the discovery of new treatment options but should also investigate common key aspects of treatment, particularly the following.

- When is the optimal time point to start antiviral therapy, what is the required duration, and when is it too late to initiate treatment?

- In line with the open questions regarding dexamethasone, when is it time to start anti-inflammatory drugs and which biomarkers can we use to tailor this therapy?

- What role can the individualization of therapy based on dose adaption and therapeutic drug monitoring (TDM) play in the treatment of COVID-19?

Meanwhile, due to the lack of highly effective and sufficiently evaluated treatment options, the most important strategy currently is avoidance of infection by the implementation of optimal public health measures that incorporate appropriate handwashing and social distancing. Furthermore, the use of rapid diagnostic tests to identify silent carriers, along with active disease, and the availability of personal protective equipment to protect from transmission, are critical to limit the massive spread of infection. Lastly, the development of vaccines (in which a clinical trial has been initiated in the US) is vital to immediately protect individual immunity and our global community long-term.

Acknowledgements Open access funding provided by Medical University of Vienna. This review was performed by members of the PK/ PD of Anti-Infectives Study Group (EPASG) of the European Society of Clinical Microbiology and Infectious Diseases (ESCMID). JFS was funded by a United Kingdom Medical Research Council Fellowship (MR/M008665/1). JAR would like to acknowledge funding from the Australian National Health and Medical Research Council for a Centre of Research Excellence (APP1099452) and a Practitioner Fellowship (APP1117065)

Funding No funding was received for this manuscript.

\section{Compliance with Ethical Standards}

Conflict of interest Markus Zeitlinger, Birgit C.P. Koch, Roger J.M. Bruggemann, Pieter de Cock, Timothy Felton, Maya Christina Hites, Jennifer Le, Sonia Luque, Alasdair Peter Macgowan, Deborah J.E.
Marriott, Anouk E. Muller, Kristina Nadrah, David L. Paterson, Joseph F. Standing, João Paulo Marochi Telles, Michael Christoph Wölfl-Duchek, Michael Thy and Jason Roberts declare they have no conflicts of interest associated with the content of the current manuscript.

Open Access This article is licensed under a Creative Commons Attribution-NonCommercial 4.0 International License, which permits any non-commercial use, sharing, adaptation, distribution and reproduction in any medium or format, as long as you give appropriate credit to the original author(s) and the source, provide a link to the Creative Commons licence, and indicate if changes were made. The images or other third party material in this article are included in the article's Creative Commons licence, unless indicated otherwise in a credit line to the material. If material is not included in the article's Creative Commons licence and your intended use is not permitted by statutory regulation or exceeds the permitted use, you will need to obtain permission directly from the copyright holder. To view a copy of this licence, visit http://creativecommons.org/licenses/by-nc/4.0/.

\section{References}

1. Totura AL, Bavari S. Broad-spectrum coronavirus antiviral drug discovery. Expert Opin Drug Discov. 2019;14(4):397-412.

2. Roberts JA, Abdul-Aziz MH, Lipman J, et al. Individualised antibiotic dosing for patients who are critically ill: challenges and potential solutions. Lancet Infect Dis. 2014;14(6):498-509.

3. Liverpool Uo. Covid-19 drug interactions. https://www.covid 19-druginteractionsorg/. Accessed 17 July 2020.

4. WHO. Global research on coronavirus disease (COVID-19). https ://www.whoint/emergencies/diseases/novel-coronavirus-2019/ global-research-on-novel-coronavirus-2019-ncov. Accessed 17 July 2020.

5. Elsevier. Clinical Pharmacology. https://www.clinicalpharmac ologycom/. Accessed 17 July 2020.

6. Talal AH, Ribeiro RM, Powers KA, et al. Pharmacodynamics of PEG-IFN alpha differentiate HIV/HCV coinfected sustained virological responders from nonresponders. Hepatology. 2006;43(5):943-53.

7. Yao X, Ye F, Zhang M, et al. In vitro antiviral activity and projection of optimized dosing design of hydroxychloroquine for the treatment of severe acute respiratory syndrome coronavirus 2 (SARS-CoV-2). Clin Infect Dis. 2020. https://doi.org/10.1093/ cid/ciaa237 (Epub 9 Mar 2020).

8. Fan J, Zhang X, Liu J, et al. Connecting hydroxychloroquine in vitro antiviral activity to in vivo concentration for prediction of antiviral effect: a critical step in treating COVID-19 patients. Clin Infect Dis. 2020. https://doi.org/10.1093/cid/ciaa623 (Epub 21 May 2020).

9. Liu J, Cao R, Xu M, et al. Hydroxychloroquine, a less toxic derivative of chloroquine, is effective in inhibiting SARS-CoV-2 infection in vitro. Cell Discov. 2020;6:16.

10. Borba MGS, Val FFA, Sampaio VS, et al. Effect of high vs low doses of chloroquine diphosphate as adjunctive therapy for patients hospitalized with severe acute respiratory syndrome coronavirus 2 (SARS-CoV-2) infection: a randomized clinical trial. JAMA Netw Open. 2020;3(4):e208857.

11. Mehra MR, Desai SS, Ruschitzka F, Patel AN. Hydroxychloroquine or chloroquine with or without a macrolide for treatment of COVID-19: a multinational registry analysis. Lancet. 2020. https://doi.org/10.1016/S0140-6736(20)31180-6 (Epub 22 May 2020). 
12. Geleris J, Sun Y, Platt J, et al. Observational study of hydroxychloroquine in hospitalized patients with Covid-19. N Engl J Med. 2020;382(25):2411-8.

13. Boulware DR, Pullen MF, Bangdiwala AS, et al. A randomized trial of hydroxychloroquine as postexposure prophylaxis for Covid-19. N Engl J Med. 2020. https://doi.org/10.1056/NEJMo a2016638 (Epub 3 Jun 2020).

14. Beigel JH, Tomashek KM, Dodd LE, et al. Remdesivir for the treatment of Covid-19- preliminary report. N Engl J Med. 2020. https://doi.org/10.1056/NEJMc2022236 (Epub 10 Jul 2020).

15. Chu CM, Cheng VC, Hung IF, et al. Role of lopinavir/ritonavir in the treatment of SARS: initial virological and clinical findings. Thorax. 2004;59(3):252-6.

16. Yamamoto N, Yang R, Yoshinaka Y, et al. HIV protease inhibitor nelfinavir inhibits replication of SARS-associated coronavirus. Biochem Biophys Res Commun. 2004;318(3):719-25.

17. Chan JF, Chan KH, Kao RY, et al. Broad-spectrum antivirals for the emerging Middle East respiratory syndrome coronavirus. J Infect. 2013;67(6):606-16.

18. Mercuro NJ, Yen CF, Shim DJ, et al. Risk of QT interval prolongation associated with use of hydroxychloroquine with or without concomitant azithromycin among hospitalized patients testing positive for coronavirus disease 2019 (COVID-19). JAMA Cardiol. 2020. https://doi.org/10.1001/jamacardio.2020.1834 (Epub 1 May 2020).

19. Meid AD, Bighelli I, Machler S, et al. Combinations of QTcprolonging drugs: towards disentangling pharmacokinetic and pharmacodynamic effects in their potentially additive nature. Ther Adv Psychopharmacol. 2017;7(12):251-64.

20. Pea F, Furlanut M. Pharmacokinetic aspects of treating infections in the intensive care unit: focus on drug interactions. Clin Pharmacokinet. 2001;40(11):833-68.

21. Horby P, Lim WS, Emberson J, Mafham M, Bell J, Linsell L. Effect of dexamethasone in hospitalized patients with COVID-19: preliminary report. Medrxiv. 2020. https://doi. org/10.1101/2020.06.22.20137273v1.

22. Villikka K, Kivisto KT, Neuvonen PJ. The effect of dexamethasone on the pharmacokinetics of triazolam. Pharmacol Toxicol. 1998;83(3):135-8.

23. Hahn J, Choi JH, Chang MJ. Pharmacokinetic changes of antibiotic, antiviral, antituberculosis and antifungal agents during extracorporeal membrane oxygenation in critically ill adult patients. J Clin Pharm Ther. 2017;42(6):661-71.

24. Shekar K, Fraser JF, Smith MT, Roberts JA. Pharmacokinetic changes in patients receiving extracorporeal membrane oxygenation. J Crit Care. 2012;27(6):741.e749-718.

25. Van Stone JC. Hemodialysis and chloroquine poisoning. J Lab Clin Med. 1976;88(1):87-90.

26. Eyler RF, Mueller BA. Antibiotic dosing in critically ill patients with acute kidney injury. Nat Rev Nephrol. 2011;7(4):226-35.

27. Vossen MG, Thalhammer F. Effects of renal replacement therapy on antimicrobial therapy. Curr Clin Pharmacol. 2013;8(1):39-45.

28. Vincent HH, Vos MC, Akcahuseyin E, Goessens WH, van Duyl WA, Schalekamp MA. Drug clearance by continuous haemodiafiltration. Analysis of sieving coefficients and mass transfer coefficients of diffusion. Blood Purif. 1993;11(2):99-107.

29. Pea F, Viale P, Pavan F, Furlanut M. Pharmacokinetic considerations for antimicrobial therapy in patients receiving renal replacement therapy. Clin Pharmacokinet. 2007;46(12):997-1038.

30. Akintonwa A, Odutola TA, Edeki T, Mabadeje AF. Hemodialysis clearance of chloroquine in uremic patients. Ther Drug Monit. 1986;8(3):285-7.

31. Gupta SK, Rosenkranz SL, Cramer YS, et al. The pharmacokinetics and pharmacogenomics of efavirenz and lopinavir/ ritonavir in HIV-infected persons requiring hemodialysis. AIDS 2008;22(15):1919-27.

32. Favie LM, Murk JL, Meijer A, Nijstad AL, van Maarseveen EM, Sikma MA. Pharmacokinetics of favipiravir during continuous venovenous haemofiltration in a critically ill patient with influenza. Antiviral Ther. 2018;23(5):457-61.

33. Shuster DL, Menon RM, Ding B, et al. Effects of chronic kidney disease stage 4 , end-stage renal disease, or dialysis on the plasma concentrations of ombitasvir, paritaprevir, ritonavir, and dasabuvir in patients with chronic HCV infection: pharmacokinetic analysis of the phase 3 RUBY-I and RUBY-II trials. Eur J Clin Pharmacol. 2019;75(2):207-16.

34. Gupta SK, Kantesaria B, Glue P. Pharmacokinetics, safety, and tolerability of ribavirin in hemodialysis-dependent patients. Eur J Clin Pharmacol. 2012;68(4):415-8.

35. Gotoh A, Hara I, Fujisawa M, et al. Pharmacokinetics of natural human IFN-alpha in hemodialysis patients. J Interferon Cytokine Res. 1999;19(10):1117-23.

36. Serra DB, Sun H, Karwowska S, Praestgaard J, Halabi A, Stein DS. Single-dose pharmacokinetics, safety, and tolerability of albinterferon alfa- $2 \mathrm{~b}$ in subjects with end-stage renal disease on hemodialysis compared to those in matched healthy volunteers. Antimicrob Agents Chemother. 2011;55(2):473-7.

37. Cao B, Wang Y, Wen D, et al. A trial of lopinavir-ritonavir in adults hospitalized with severe Covid-19. N Engl J Med. 2020;382(19):1787-99.

38. Chan KS, Lai ST, Chu CM, et al. Treatment of severe acute respiratory syndrome with lopinavir/ritonavir: a multicentre retrospective matched cohort study. Hong Kong Med J. 2003;9(6):399-406.

39. WHO. Summaries of evidence from selected experimental therapeutics. https://www.whoint/ebola/drc-2018/summaries-of-evide nce-experimental-therapeuticspdf?ua=1. Accessed 17 July 2020.

40. Savarino A, Boelaert JR, Cassone A, Majori G, Cauda R. Effects of chloroquine on viral infections: an old drug against today's diseases? Lancet Infect Dis. 2003;3(11):722-7.

41. Aidsinfo.nih. Guidelines for the use of antiretroviral agents in pediatric HIV infection. https://www.aidsinfonihgov/guidelines /html/2/pediatric-arv/132/lopinavir-ritonavir. Accessed 17 July 2020.

42. Hsu A, Granneman GR, Bertz RJ. Ritonavir. Clinical pharmacokinetics and interactions with other anti-HIV agents. Clin Pharmacokinet. 1998;35(4):275-91.

43. Hayden FG, Shindo N. Influenza virus polymerase inhibitors in clinical development. Curr Opin Infect Dis. 2019;32(2):176-86.

44. Dong L, Hu S, Gao J. Discovering drugs to treat coronavirus disease 2019 (COVID-19). Drug Discov Ther. 2020;14(1):58-60.

45. Shen K, Yang Y, Wang T, et al. Diagnosis, treatment, and prevention of 2019 novel coronavirus infection in children: experts' consensus statement. World J Pediatr. 2020;16(3):223-31.

46. Deng P, Zhong D, Yu K, Zhang Y, Wang T, Chen X. Pharmacokinetics, metabolism, and excretion of the antiviral drug arbidol in humans. Antimicrob Agents Chemother. 2013;57(4):1743-55.

47. Wills RJ. Clinical pharmacokinetics of interferons. Clin Pharmacokinet. 1990;19(5):390-9.

48. Jin YH, Cai L, Cheng ZS, et al. A rapid advice guideline for the diagnosis and treatment of 2019 novel coronavirus (2019$\mathrm{nCoV}$ ) infected pneumonia (standard version). Mil Med Res. 2020;7(1):4.

49. Midgley I, Hood AJ, Proctor P, et al. Metabolic fate of $14 \mathrm{C}$-camostat mesylate in man, rat and dog after intravenous administration. Xenobiotica. 1994;24(1):79-92.

50. Yuhara H, Ogawa M, Kawaguchi Y, Igarashi M, Shimosegawa T, Mine T. Pharmacologic prophylaxis of post-endoscopic retrograde cholangiopancreatography pancreatitis: protease 
inhibitors and NSAIDs in a meta-analysis. J Gastroenterol. 2014;49(3):388-99.

51. Cao YG, Chen YC, Hao K, Zhang M, Liu XQ. An in vivo approach for globally estimating the drug flow between blood and tissue for nafamostat mesilate: the main hydrolysis site determination in human. Biol Pharm Bull. 2008;31(11):1985-9.

52. Kucers' the use of antibiotics: a clinical review of antibacterial, antifungal, antiparasitic, and antiviral drugs, Seventh Edition, Taylor \& Francis Inc; (2. Oktober 2017)

53. Wang M, Cao R, Zhang L, et al. Remdesivir and chloroquine effectively inhibit the recently emerged novel coronavirus (2019nCoV) in vitro. Cell Res. 2020;30(3):269-71.

54. Choy KT, Wong AY, Kaewpreedee P, et al. Remdesivir, lopinavir, emetine, and homoharringtonine inhibit SARS-CoV-2 replication in vitro. Antiviral Res. 2020;178:104786.

55. Sheahan TP, Sims AC, Leist SR, et al. Comparative therapeutic efficacy of remdesivir and combination lopinavir, ritonavir, and interferon beta against MERS-CoV. Nat Commun. 2020;11(1):222.

56. Warren TK, Jordan R, Lo MK, et al. Therapeutic efficacy of the small molecule GS-5734 against Ebola virus in rhesus monkeys. Nature. 2016;531(7594):381-5.

57. Wang Y, Zhang D, Du G, et al. Remdesivir in adults with severe COVID-19: a randomised, double-blind, placebo-controlled, multicentre trial. Lancet. 2020;395(10236):1569-78.

58. Tasanor O, Noedl H, Na-Bangchang K, Congpuong K, Sirichaisinthop J, Wernsdorfer WH. An in vitro system for assessing the sensitivity of plasmodium vivax to chloroquine. Acta Trop. 2002;83(1):49-61.

59. Savarino A, Gennero L, Chen HC, et al. Anti-HIV effects of chloroquine: mechanisms of inhibition and spectrum of activity. AIDS. 2001;15(17):2221-9.

60. de Wilde AH, Jochmans D, Posthuma CC, et al. Screening of an FDA-approved compound library identifies four small-molecule inhibitors of Middle East respiratory syndrome coronavirus replication in cell culture. Antimicrob Agents Chemother. 2014;58(8):4875-84.

61. Mackenzie AH. Dose refinements in long-term therapy of rheumatoid arthritis with antimalarials. Am J Med. 1983;75(1a):40-5.

62. Dickinson L, Boffito M, Back D, et al. Sequential population pharmacokinetic modeling of lopinavir and ritonavir in healthy volunteers and assessment of different dosing strategies. Antimicrob Agents Chemother. 2011;55(6):2775-822.

63. Hung IF, Lung KC, Tso EY, et al. Triple combination of interferon beta-1b, lopinavir-ritonavir, and ribavirin in the treatment of patients admitted to hospital with COVID-19: an open-label, randomised, phase 2 trial. Lancet. 2020;395(10238):1695-704.

64. Oestereich L, Ludtke A, Wurr S, Rieger T, Munoz-Fontela C, Gunther S. Successful treatment of advanced Ebola virus infection with T-705 (favipiravir) in a small animal model. Antiviral Res. 2014;105:17-211.

65. Bixler SL, Bocan TM, Wells J, et al. Efficacy of favipiravir (T-705) in nonhuman primates infected with Ebola virus or Marburg virus. Antiviral Res. 2018;151:97-104.

66. Nguyen TH, Guedj J, Anglaret X, et al. Favipiravir pharmacokinetics in Ebola-Infected patients of the JIKI trial reveals concentrations lower than targeted. PLoS Negl Trop Dis. 2017;11(2):e0005389.

67. Cai Q, Yang M, Liu D, et al. Experimental treatment with favipiravir for COVID-19: an open-label control study. Engineering (Beijing). 2020. https://doi.org/10.1016/j.eng.2020.03.007 (Epub 18 Mar 2020).

68. Fuchs EJ, Kiser JJ, Hendrix CW, et al. Plasma and intracellular ribavirin concentrations are not significantly altered by abacavir in hepatitis $\mathrm{C}$ virus-infected patients. J Antimicrob Chemother. 2016;71(6):1597-600.
69. Wang X, Cao R, Zhang H, et al. The anti-influenza virus drug, arbidol is an efficient inhibitor of SARS-CoV-2 in vitro. Cell Discov. 2020;6:28.

70. Brooks MJ, Burtseva EI, Ellery PJ, et al. Antiviral activity of arbidol, a broad-spectrum drug for use against respiratory viruses, varies according to test conditions. J Med Virol. 2012;84(1):170-81.

71. Sun Y, He X, Qiu F, et al. Pharmacokinetics of single and multiple oral doses of arbidol in healthy Chinese volunteers. Int J Clin Pharmacol Ther. 2013;51(5):423-32.

72. Lian N, Xie H, Lin S, Huang J, Zhao J, Lin Q. Umifenovir treatment is not associated with improved outcomes in patients with coronavirus disease 2019: a retrospective study. Clin Microbiol Infect. 2020;26(7):917-21.

73. Mok CC, Penn HJ, Chan KL, Tse SM, Langman LJ, Jannetto PJ. Hydroxychloroquine serum concentrations and flares of systemic lupus erythematosus: a longitudinal cohort analysis. Arthritis Care Res. 2016;68(9):1295-302.

74. Kumar A, Liang B, Aarthy M, et al. Hydroxychloroquine inhibits zika virus NS2B-NS3 protease. ACS Omega. 2018;3(12):18132-41.

75. Zheng L, Li MP, Gou ZP, et al. A pharmacokinetic and pharmacodynamic comparison of a novel pegylated recombinant consensus interferon-alpha variant with peginterferon-alpha-2a in healthy subjects. Br J Clin Pharmacol. 2015;79(4):650-9.

76. Hart BJ, Dyall J, Postnikova E, et al. Interferon-beta and mycophenolic acid are potent inhibitors of Middle East respiratory syndrome coronavirus in cell-based assays. J Gen Virol. 2014;95(Pt 3):571-7.

77. Hegen H, Auer M, Deisenhammer F. Pharmacokinetic considerations in the treatment of multiple sclerosis with interferon-beta. Expert Opin Drug Metab Toxicol. 2015;11(12):1803-19.

78. Hoffmann M, Kleine-Weber H, Schroeder S, et al. SARS-CoV-2 cell entry depends on ACE2 and TMPRSS2 and is blocked by a clinically proven protease inhibitor. Cell. 2020;181(2):271-280. e278.

79. Hoffmann M, Schroeder S, Kleine-Weber H, Müller MA, Drosten C, Pöhlmann S. Nafamostat mesylate blocks activation of SARSCoV-2: new treatment option for COVID-19. Antimicrob Agents Chemother. 2020;64(6):e00754-e820.

80. Cao YG, Zhang M, Yu D, Shao JP, Chen YC, Liu XQ. A method for quantifying the unstable and highly polar drug nafamostat mesilate in human plasma with optimized solid-phase extraction and ESI-MS detection: more accurate evaluation for pharmacokinetic study. Anal Bioanal Chem. 2008;391(3):1063-71.

81. Clinical Pharmacology Interaction Report. https://www.clini calpharmacology-ip.com/Forms/Reports/intereport.aspx; https ://www.clinicalpharmacology-ip.com/Forms/Reports/intereport aspx. Accessed 13 Mar 2020.

82. ClinicalTrials.gov. The efficacy of lopinavir plus ritonavir and arbidol against novel coronavirus infection (ELACOI). https:// www.clinicaltrialsgov/ct2/show/NCT04252885? cond=Coron avirus\&draw $=3 \&$ rank $=12$. Accessed 17 July 2020 .

83. Park SY, Lee JS, Son JS, et al. Post-exposure prophylaxis for Middle East respiratory syndrome in healthcare workers. J Hosp Infect. 2019;101(1):42-6.

84. Chen F, Chan KH, Jiang Y, et al. In vitro susceptibility of 10 clinical isolates of SARS coronavirus to selected antiviral compounds. J Clin Virol. 2004;31(1):69-75.

85. Wang Z, Chen X, Lu Y, Chen F, Zhang W. Clinical characteristics and therapeutic procedure for four cases with 2019 novel coronavirus pneumonia receiving combined Chinese and Western medicine treatment. Biosci Trends. 2020;14(1):64-8.

86. Xia J, Rong L, Sawakami T, et al. Shufeng Jiedu Capsule and its active ingredients induce apoptosis, inhibit migration and invasion, and enhances doxorubicin therapeutic 
efficacy in hepatocellular carcinoma. Biomed Pharmacother. 2018;99:921-30.

87. Yao TT, Qian JD, Zhu WY, Wang Y, Wang GQ. A systematic review of lopinavir therapy for SARS coronavirus and MERS coronavirus - a possible reference for coronavirus disease-19 treatment option. J Med Virol. 2020;92(6):556-63.

88. Registry CCT. A real-world study for lopinavir/ritonavir (LPV/r) and emtritabine (FTC)/tenofovir alafenamide fumarate tablets (TAF) regimen in the treatment of novel coronavirus pneumonia (COVID-19). https://www.chictrorgen/showprojen aspx?proj=48919. Accessed 17 July 2020.

89. Zeng YM, Xu XL, He XQ, et al. Comparative effectiveness and safety of ribavirin plus interferon-alpha, lopinavir/ritonavir plus interferon-alpha, and ribavirin plus lopinavir/ritonavir plus interferon-alpha in patients with mild to moderate novel coronavirus disease 2019: study protocol. Chin Med J. 2020;133(9):1132-4.

90. Arabi YM, Shalhoub S, Mandourah Y, et al. Ribavirin and interferon therapy for critically ill patients with Middle East respiratory syndrome: a multicenter observational study. Clin Infect Dis. 2020;70(9):1837-44.

91. Omrani AS, Saad MM, Baig K, et al. Ribavirin and interferon alfa-2a for severe Middle East respiratory syndrome coronavirus infection: a retrospective cohort study. Lancet Infect Dis. 2014;14(11):1090-5.

92. Stockman LJ, Bellamy R, Garner P. SARS: systematic review of treatment effects. PLoS Med. 2006;3(9):e343.

93. Morgenstern B, Michaelis M, Baer PC, Doerr HW, Cinatl J Jr. Ribavirin and interferon-beta synergistically inhibit SARS-associated coronavirus replication in animal and human cell lines. Biochem Biophys Res Commun. 2005;326(4):905-8.

94. Kim UJ, Won EJ, Kee SJ, Jung SI, Jang HC. Combination therapy with lopinavir/ritonavir, ribavirin and interferon-alpha for Middle East respiratory syndrome. Antivir Ther. 2016;21(5):455-9.
95. Spanakis N, Tsiodras S, Haagmans BL, et al. Virological and serological analysis of a recent Middle East respiratory syndrome coronavirus infection case on a triple combination antiviral regimen. Int J Antimicrob Agents. 2014;44(6):528-32.

96. Gautret PLP, Parola P, Hoang V, Meddeb L, Mailhe M, et al. Hydroxychloroquine and azithromycin as a treatment of COVID19: results of an open-label non-randomized clinical trial. Int J Antimicrob Agents. 2020. https://doi.org/10.1016/j.ijantimica g.2020.105949 (Epub 20 Mar 2020).

97. Gautret P, Lagier JC, Parola P, et al. Clinical and microbiological effect of a combination of hydroxychloroquine and azithromycin in 80 COVID-19 patients with at least a six-day follow up: a pilot observational study. Trav Med Infect Dis. 2020;34:101663.

98. Rosenberg ES, Dufort EM, Udo T, et al. Association of treatment with hydroxychloroquine or azithromycin with in-hospital mortality in patients with COVID-19 in New York state. JAMA. 2020;323(24):2493-502.

99. Million M, Lagier JC, Gautret P, et al. Early treatment of COVID19 patients with hydroxychloroquine and azithromycin: a retrospective analysis of 1061 cases in Marseille, France. Trav Med Infect Dis. 2020;35:101738.

100. Maisonnasse P, Guedj J, Contreras V, et al. Hydroxychloroquine in the treatment and prophylaxis of SARS-CoV-2 infection in non-human primates. 2020. https://doi.org/10.21203/ rs.3.rs-27223/v1.

101. Bugge JF. Pharmacokinetics and drug dosing adjustments during continuous venovenous hemofiltration or hemodiafiltration in critically ill patients. Acta Anaesthesiol Scand. 2001;45(8):929-34.

102. Toutain PL, Bousquet-Melou A. Volumes of distribution. J Vet Pharmacol Ther. 2004;27(6):441-53.

\section{Affiliations}

\section{Markus Zeitlinger ${ }^{1}(1) \cdot$ Birgit C. P. Koch ${ }^{2} \cdot$ Roger Bruggemann $^{3} \cdot$ Pieter De Cock ${ }^{4}$ Timothy Felton ${ }^{5,6} \cdot$ Maya Hites $^{7}$. Jennifer Le ${ }^{8}$. Sonia Luque ${ }^{9,10}$. Alasdair P. MacGowan ${ }^{11}$. Deborah J. E. Marriott ${ }^{12,13}$. Anouk E. Muller ${ }^{14}$. Kristina Nadrah ${ }^{15,16}$. David L. Paterson ${ }^{17,18}$. Joseph F. Standing ${ }^{19,20}$. João P. Telles ${ }^{21}$. Michael Wölfl-Duchek ${ }^{22}$. Michael Thy ${ }^{23,24}$. Jason A. Roberts $25,26,27,28,29$ - the PK/PD of Anti-Infectives Study Group (EPASG) of the European Society of Clinical Microbiology, Infectious Diseases (ESCMID)}

1 Department of Clinical Pharmacology, Medical University of Vienna, Währinger Gürtel 18-20, 1090 Vienna, Austria

2 Hospital Pharmacy, Erasmus MC, Rotterdam, The Netherlands

3 Radboud University Medical Center, Nijmegen, The Netherlands

4 Department of Pharmacy 2, Heymans Institute of Pharmacology, Ghent University Hospital, Ghent University, Ghent, Belgium

5 Division of Infection, Immunity and Respiratory Medicine, Faculty of Biology, Medicine and Health, The University of Manchester, Manchester, UK

6 Intensive Care Unit, Wythenshawe Hospital, Manchester University NHS Foundation Trust, Manchester, UK
7 Clinic of Infectious Diseases, CUB-Erasme Hospital, Université Libre de Bruxelles, Brussels, Belgium

8 Skaggs School of Pharmacy and Pharmaceutical Sciences, University of California San Diego, San Diego, CA, USA

9 Pharmacy Department, Hospital del Mar, Parc de Salut Mar, Barcelona, Spain

10 Infectious Pathology and Antimicrobials Research Group (IPAR), Institut Hospital del Mar D'Investigacions Mèdiques (IMIM), Barcelona, Spain

11 Bristol Centre for Antimicrobial Research and Evaluation, Infection Sciences, Severn Pathology Partnership, North Bristol NHS Trust, Southmead Hospital, Westbury-On-Trym, Bristol, UK

12 St. Vincent's Hospital, Darlinghurst, NSW, Australia

13 University of New South Wales, Sydney, NSW, Australia 
14 HaaglandenMC, The Hague and ErasmusMC, Rotterdam, The Netherlands

15 Department of Infectious Diseases, University Medical Centre Ljubljana, Ljubljana, Slovenia

16 Faculty of Medicine, University of Ljubljana, Ljubljana, Slovenia

17 University of Queensland Centre for Clinical Research, Faculty of Medicine, The University of Queensland, Brisbane, QLD, Australia

18 Department of Infectious Diseases, Royal Brisbane and Women's Hospital, Brisbane, QLD, Australia

19 Infection, Inflammation and Immunity, Great Ormond Street Institute of Child Health, University College London, London, UK

20 Department of Pharmacy, Great Ormond Street Hospital for Children, London, UK

21 Department of Infectious Diseases, AC Camargo Cancer Center, São Paulo, SP, Brazil

22 Department of Clinical Pharmacology, Medical University of Vienna, Vienna, Austria
23 Infectious Diseases Department and Intensive Care Unit, Hospital Bichat, Paris, France

24 EA7323, Evaluation of Perinatal and Paediatric Therapeutics and Pharmacology, University Paris Descartes, Paris, France

25 University of Queensland Centre for Clinical Research, Faculty of Medicine and Centre for Translational Anti-Infective Pharmacodynamics, School of Pharmacy, The University of Queensland, Brisbane, QLD, Australia

26 Department of Pharmacy, Royal Brisbane and Women's Hospital, Brisbane, QLD, Australia

27 Department of Intensive Care Medicine, Royal Brisbane and Women's Hospital, Brisbane, QLD, Australia

28 Division of Anaesthesiology Critical Care Emergency and Pain Medicine, Nîmes University Hospital, University of Montpellier, Nîmes, France

29 The University of Queensland Centre for Clinical Research, The University of Queensland, Royal Brisbane and Women's Hospital, Butterfield St, Herston, QLD 4029, Australia 